Max-Planck-Institut für demografische Forschung

Max Planck Institute for Demographic Research

Konrad-Zuse-Strasse 1 - D-18057 Rostock - GERMANY

Tel +49 (0) 3812081 - 0; Fax +49 (0) 3812081 - 202;

http://www.demogr.mpg.de

MPIDR WORKING PAPER WP 2009-045

DECEMBER 2009

\title{
Declining fertility in Ukraine: \\ What is the role of abortion and contraception?
}

Nataliia Levchuk (nlevchuk@mail.ru)

Brienna Perelli-Harris (perelli@demogr.mpg.de)

This working paper has been approved for release by: Heiner Maier (maier@demogr.mpg.de), Dean of the International Max Planck Research School for Demography

(C) Copyright is held by the authors.

Working papers of the Max Planck Institute for Demographic Research receive only limited review. Views or opinions expressed in working papers are attributable to the authors and do not necessarily reflect those of the Institute. 


\title{
Declining fertility in Ukraine: What is the role of abortion and contraception?
}

\author{
Nataliia Levchuk ${ }^{*}$ and Brienna Perelli-Harris ${ }^{* *}$
}

* Institute of Demography and Social Studies at the National Academy of Sciences of Ukraine E-mail:nlevchuk@mail.ru

** Max Planck Institute for Demographic Research, Germany

E-mail: perelli@demogr.mpg.de

Acknowledgements: We would like to thank Aiva Jasilioniene, Michaela Kreyenfeld and Rainer Walke for their valuable comments and helpful suggestions while conducting this research. 


\begin{abstract}
In this paper we analyze the changing relationship between childbearing and abortion in Ukraine, which has had one of the world's highest abortion rates and lowest fertility rates. Using the 2007 Ukrainian Demographic and Health Survey, we examine changes in abortion before and after the dramatic fertility decline. We estimate event history models for first abortions as well as competing risks hazards by pregnancy outcome. Our results show that although abortion rates rapidly declined in the 1990s, abortions have impacted fertility by lowering second birth rates. On the other hand, abortions have been used less frequently for postponing first births, as is more common in developed countries. We also describe how this relationship has been maintained through the slow adoption of modern contraception. Thus, Ukraine represents a country with an unusual relationship between fertility, abortion, and contraception, and where low fertility has been achieved with little reliance on modern methods.
\end{abstract}




\section{Contents}

1. Introduction 4

2. Theoretical framework $\quad 6$

2.1. The relationship between fertility, abortion and contraception 6

2.2. Abortion, fertility and contraception in Ukraine 8

3. Data and methods 12

3.1. Data $\quad 12$

3.2. Method 12

3.3. Explanatory variables 14

3.4. Control variables 15

4. Results 16

4.1. Pregnancy, abortion and childbearing: general analysis 16

4.2. Age-profile of first abortion: effect of early childbearing 17

$\begin{array}{ll}\text { 4.3. Period changes: decreases in abortion over time } & 18\end{array}$

4.4. The link between first abortion and childbearing 19

4.5. Shift in first abortion pattern by parity and cohort 19

4.6. The role of control variables 20

4.7. Competing risks by pregnancy order: abortion versus live birth 21

$\begin{array}{ll}\text { 5. Conclusions } & 24\end{array}$

References $\quad 28$

Figures and Tables $\quad 33$

Appendixes $\quad 44$ 


\section{Introduction}

One of the most remarkable phenomena of the late $20^{\text {th }}$ century was the emergence of very low fertility - or a TFR below 1.3 - in 24 countries of the industrialized world (Kohler, Billari, Ortega 2002; Goldstein et al. 2009). The reasons for this decline have been investigated in a number of contexts (Frejka et al. 2008, Caldwell and Schindlmayr 2003), but very few studies have examined how fertility declined so low, or what contraceptive methods were employed. In Western Europe, the assumption has been that modern contraceptive technology was essential to declining fertility, namely the pill, IUD, condoms, and other methods (David 1992; Blayo 1995; Frejka 2008), although in some countries such as Southern Europe, the spread of these methods was slower and reliance on coitus interruptus lasted into the 1990s (Dalla Zuanna et al. 2005; Gribaldo et al. 2009). Eastern Europe, however, achieved very low fertility with relatively ineffective contraception and a high prevalence of abortion. This raises the question of to what extent abortion fuelled the decline to very low fertility. An additional complicating factor is that abortion rates were declining in Eastern Europe as fertility declined (Henshaw et al. 1999; Sedgh at al. 2007), making the relative role of abortion less clear.

This study tries to disentangle the fertility-abortion puzzle in Ukraine, which had the world's highest abortion rates in the early 1990s (WHO HFA-DB) and the world's lowest fertility rates in the late 1990s (COE) (see Figure 1). Although it would appear that high abortion rates would naturally facilitate the decline to lowest-low fertility, the relationship is not so simple. Ukraine's initial decline to low fertility was driven by the postponement or elimination of second births (Perelli-Harris 2005), rather than the postponement of first births, which spurred the very low fertility in Southern and Central Europe (Kohler, Billari, Ortega 2002; Dalla Zuanna 2001). Following a long historical tradition, first births in Ukraine were nearly universal and relatively early. Thus, abortion has primarily been used for stopping and spacing, not for the postponement of first births as in the West (Anderson 1991; Westoff 2005; Perelli-Harris 2005). Starting in the mid1990s, the pattern of fertility began to change. Gradually, first births were postponed, and the mean 
age at first birth began to increase. In 2002, fertility began to increase again, with the most recent data indicating some recovery in total fertility to the level of 1.35 in 2007 . Simultaneously, abortion rates rapidly declined, although they remained much higher than in the West.

This unusual pattern leads to several interesting questions. With the decline in both fertility and abortion in the 1990s, how did the relationship between fertility and abortion change? Did the parity-specific pattern of abortion change? Did women begin to use abortion to postpone childbearing, more so than in the past or did abortion remain an important means of limiting family size? How has increasing contraceptive use facilitated this changing relationship? Has the type of contraception adopted truly negated the reliance on abortion, and will the historically ingrained "abortion culture" in Ukraine disappear?

\section{Figure 1 about here}

Ukraine is also an interesting case study, because of the rapid social and economic change that occurred after the disintegration of the Soviet Union. Although other studies have discussed the high level and determinants of abortion in the former USSR (Westoff 2000, 2005; Westoff and Serbanescu 2008; Agadjanian 2002; Agadjanian and Qian 1997; Zakharov and Sakevich 2007; Trevitt and Astone 2009), none have specifically investigated how abortion changes over time and by parity. In addition, most studies have been done in the countries of the Caucasus and Central Asia regions, where fertility rates have not declined below 1.3. Given the unusual fertility and abortion pattern in Ukraine, it is important to analyse how these pregnancy outcomes changed during such a period of instability.

In addition, this study employs individual-level data and a life course approach. Employing event-history analysis we first focus our attention on first abortion, which constitutes an important determinant of the observed fertility level in Ukraine. We analyse the key-factors affecting the risk of first abortion and examine the changes in abortion-parity relations over time, before and after the dramatic decline in fertility. Then, in order to understand the extent to which abortions contribute to parity-specific fertility we estimate a competing risks hazard model for pregnancy outcome - 
abortion versus live birth - by pregnancy order. To our knowledge, this method is a new way of examining the relationship between abortion and fertility, and represents the alternate decisions that can be made after a pregnancy is underway. Although the main focus here is on the changing relationship between abortion and fertility, other important covariates are also considered (like region and place of residence, religious affiliation) which can improve our understanding of the socio-demographic context of the persistent high level of abortion in Ukraine.

\section{Theoretical framework}

\subsection{The relationship between fertility, abortion, and contraception}

As has been noted in other studies (Bongaarts 1978; Bongaarts and Westoff 2000, Marston and Cleland 2003; Rossier 2003; Rossier et al. 2007; Stover 1998), abortion and contraception are alternative means to achieving the same level of fertility (assuming other proximate determinants of fertility, for example miscarriage, sexual exposure, and infertility remain constant). Thus, fertility, abortion, and contraception are fundamentally related: giving birth to a child is ultimately determined by the decision to use contraception before pregnancy and/or the decision to terminate a pregnancy after conception. Accordingly, abortion rates are higher in societies with smaller family preferences, with low contraceptive prevalence or the use of ineffective methods, and in societies with a high propensity to rely on induced abortion (Bongaarts and Westoff 2000). In addition, the persistence of positive attitudes towards abortion - or at least general acceptance - would provide a favorable environment for the higher propensity to have an abortion if the pregnancy is unintended (Frejka 1983; Stloukal 1999; David 1992).

Abortion is an important tool for controlling the timing, spacing, and stopping childbearing. As societies have moved through the fertility transition, they have experienced a substitution from traditional contraceptives to modern ones, and the recourse to abortion declined as more effective contraception was made available. This general model of the inverse relationship between contraception and induced abortion has been observed in many countries of the developed world. Indeed, the massive postponement of childbearing in Northern and Western Europe was facilitated 
by the widespread use of modern contraceptives, during the so called "contraceptive revolution" (Westoff and Ryder 1977; van de Kaa 1994; Frejka 2008). In these countries the decline in fertility was associated with the almost universal use of modern contraceptives, while abortions were employed only as a backup measure for contraceptive failure.

Nonetheless, the relationship between fertility, contraception and abortion is not linear; the pattern of contraception transition has varied across low-fertility countries. For example, the association between abortion and contraceptive was positive during the earlier stages of the fertility transition, in Korea and Cuba (Bongaarts and Westoff 2000; Marston and Cleland 2003). In these countries, increases in contraceptive use and abortion in the 1970-1980s occurred simultaneously, spurring a dramatic decline in fertility. According to Marston and Cleland (2003), the spread of effective contraception was insufficient to meet the needs of couples desiring fewer children, and thus, they had to rely on induced abortion for unintended pregnancies. After contraception became widely available, abortion was replaced by contraception and fertility stabilized at a low level. The case of Italy might be also viewed as interesting evidence of a diverging path to low fertility. Very low fertility was archived with the means of less-effective contraceptives, in particular through a high reliance on coitus interruptus, without recourse to induced abortion (Dalla Zuanna et al. 2005; De Rose et al. 2008; Gribaldo et al. 2009). Numerous cultural factors, such as individual's beliefs about health and sex, the strong influence of the Catholic Church, and the traditional gender system may have influenced the lagged adaptation of modern contraception methods in this country.

Ukraine represents another unique pattern of transition to low fertility in terms of fertility control, which challenges the conventional explanations of the path from traditional to modern contraceptive practices. First, replacement-level fertility was achieved through very low modern contraceptive use and high abortion rates. Second, the decline to very low fertility (below 1.3) was associated with a remarkable decline in abortion rates despite the very low acceptance of modern contraceptives methods such as the pill and sterilization. In the section below, we discuss the specific factors which led to this unusual pattern. 


\subsection{Abortion, fertility, and contraception in Ukraine}

In countries of the former USSR, including Ukraine, early childbearing was maintained until the 1990s, and abortion played a dominant role in family planning. Unlike in countries of the West, the liberalization of abortion occurred before the "contraceptive revolution". In 1955, legal abortion services became easily accessible, while modern contraception was unavailable to most women. (Popov 1991, 1996; Avdeev 1994; Frejka et al. 2008). Remennick (1991) has emphasized three reasons related to the principal role of abortion in family planning practices and the unique character of the fertility transition in the former USSR: isolation of the USSR from medical and contraceptive developments in the West; the traditional orientation of the Soviet health care system towards termination rather than prevention of pregnancy; and finally, socio-psychological tolerance of abortion and its perception as a routine medical procedure. Thus, the medical establishment played a prominent role in maintaining the "abortion culture" that became so prevalent during the Soviet period.

Throughout the social and economic transition in the 1990s, the patterns of family and fertility behaviour in Eastern European countries dramatically changed due to the impact of economic constraints and social disruption (Phillipov 2003), as well as the ideational change commonly associated with the "Second Demographic Transition" (Surkyn and Lesthaeghe 2004, Sobotka 2008; Perelli-Harris 2005, 2008b). In many post-socialist countries, the use of modern methods of birth control and a more responsible approach to reproductive health led to a drastic reduction in induced abortion (Sobotka et al. 2008; Muresan 2008). In Ukraine, however, the economic and social upheaval did not necessarily lead to the same changes in fertility or uptake of contraception, and declines in abortion lagged behind other post-communist countries.

Today's abortion laws in Ukraine are among the most liberal in the world ${ }^{1}$. According to official statistics, abortion rates exceeded live births rates by 1.5 times until 1988 and only fell below birth rates for the first time in 2000 (see Figure 2). Throughout the 1980s, the total abortion rates (TAR) constituted about 3.0-3.2, while the total fertility rates (TFR) were equal to 1.9-2.0. The

\footnotetext{
${ }^{1}$ Note: Abortion is accessible upon request up to the $12^{\text {th }}$ week of pregnancy, and up to 22 weeks if the mother's life is threatened or in cases of fetal abnormality.
} 
period after 1989 was characterised by remarkable simultaneous changes in both fertility and abortion trends (Steshenko 2001; Perelli-Harris 2005). The mean age at first birth hovered around 22 until the late 1990 s but increased to 23.8 by 2007, indicating a gradual postponement of first birth (Naselennya Ukrainy 2008, Perelli-Harris 2008a, 2008b). The decline in TAR was also significant. In 2000, there were 51 abortions per 100 pregnancies compared with 61 in 1990. Since 2000 official figures indicate a divergence in fertility and abortion trends: some recovery of childbearing has occurred, while abortion rates have continued to decrease.

\section{Figure 2 about here}

Although this paper focuses on the relationship between abortion and fertility, we would like to discuss the other piece of this puzzle: contraception and its specific role in Ukraine. At first glance, Ukraine appears to have experienced the same process of behavioral change in sexual and reproductive behaviour that took place in Western European countries 20 to 30 years earlier. Yet, this transition differs in terms of pace and pattern of contraception relative to childbearing. The prevalence of the use of modern contraception in soviet Ukraine started to increase after the dissolution of the USSR, but the pace of the diffusion remained slow until the end of the 1990s. Since the mid-1990s, Ukraine has adopted a number of measures to improve the reproductive health of its population. The National Programs on Reproductive Health and Family Planning (1995-2000, 2001-2005, 2006-2015) set out to develop family planning facilities and encourage individuals to take a more active role in protecting their own health (Steshenko and Irkina 1999; WHO 2008). Nonetheless, comparison of the Ukraine Reproductive and Health Survey 1999 and the Ukraine Demographic and Health Survey 2007 show that the majority of Ukrainian married women use contraceptive methods (about 67-68\% for both surveys). The use of modern methods did increase from $37.6 \%$ to $47.5 \%$ over the observed period, but it is still lower than that in Western European countries. The use of traditional methods declined from $30 \%$ to $19 \%$ and one third of women did not use any kind of contraception for different reasons (URHS 1999, UDHS 2007). 
Table 1 in about here

Despite the positive shift towards the use of modern contraceptives, a striking paradox has emerged in terms of contraception composition. Looking at the Table 1, one can notice a very low percentage of married women who used the pill and much higher percentage using the condoms. Moreover, this pattern of contraception - reluctance of the pill and preferring the condoms - does not substantially change by parity status (see Table 1). This seems to be surprising because oral contraception is one of the most popular and efficient method of pregnancy prevention in the developed world. In developed countries, women in stable sexual unions and not seeking to become pregnant mostly used the pill, IUD or sterilization (Frejka 2008). Condoms mostly spread among single sexually active people. In contrast, in Ukraine the pill accounts for only $3-5 \%$ of all contraception, sterilization for contraceptive purposes is very rare, and the condom has become the most commonly used form of modern contraception (UDHS 2007). We suggest several principal reasons for this inconsistent phenomenon.

First, the most popular modern contraceptive method in soviet Ukraine was the IUD, although the latter was implemented it the USSR much later than in Western countries (Remennick 1991). This seems to be relevant until the end of the 1990s. The UDHS survey in 2007 revealed a slight decline in the use of the IUD and a remarkable increase in the use of condom compared to the data from URHS in 1999 (URHS 1999, UDHS 2007). Unlike in countries of Western and Northern Europe where birth control is largely in the hands of women, in Ukraine women tend to rely on the "male" contraceptive methods. One possible explanation is that the use of condoms is widely advocated by various international and non-government agencies in Ukraine for the purpose of protection against sexually transmitted infections (STIs) including HIV/AIDS, both of which have spread recently to alarmingly high levels (World Bank 2006). Young people relying on condoms gain from both the prevention from STIs and unintended pregnancy, although the efficacy of this type of contraception is not high. In addition, condoms are also much cheaper and more widely available than the pill. 
In contrast, availability and awareness of the pill were very low during the Soviet period, and the pill was seen as potentially threatening health. At the present this thought is still quite widespread, and physicians are more likely to approve the IUD than the pill. This is not to say that the physicians are responsible for the low prevalence of the pill use, but rather that conservatism of the medical practitioners regarding modern contraceptive techniques has also contributed to reluctance of Ukrainian women to adopt new contraceptive behaviour. Women are still less willing to take pills because of health-related concerns (most widely believed is that the pill leads to unwanted weight gain). In addition, the pill is quite expensive, and the cost of obtaining an abortion is not high. All of these factors make the pill unpopular among Ukrainian women, although its use seems to be slightly growing over the last couple of years.

Another important issue concerns the persistent high use of traditional contraceptives: about $30 \%$ in 1999 and 19\% in 2007 (URHS 1999, UDHS 2007). Unexpectedly, the reliance on traditional methods is even growing with the increasing number of living children (see Table 1). The most popular method is withdrawal, as in other post soviet countries (Westoff 2005). Withdrawal in Ukraine has the second highest failure rate after periodic abstinence (rhythm), so women using this method are exposed to a great risk of unwanted pregnancy, which is frequently terminated by induced abortion. According to the UDHS 2007, a great percentage of women (42\%) who experienced induced abortion in the three years preceding the survey used traditional methods, only $24 \%$ used modern contraception before abortion and $34 \%$ did not use any method (UDHS 2007).

To sum up, we can conclude that Ukraine has experienced positive changes in the pattern of contraception, which are evident when we look at the downward trend of abortion. However, this conclusion should take into account the composition of contraception which favours conservative methods. The recent decline in abortion rates in Ukraine has been driven by increased contraceptive use, with growing use of the condoms and limited diffusion of the pill. The increase in condom use is positive, but seems to be problematic: lower efficacy still requires abortion as a back up option. In addition, a substantial percentage of married women continue to use traditional contraceptives 
with high failure probability and tend to seek abortion in order to terminate unwanted pregnancies (Westoff 2005). Thus, contraceptive failure accounts for most abortions in Ukraine, although the contribution of the unmet need is still relevant. Unlike the West, almost all abortions in Ukraine occur among ever-married women (UDHS 2007). Unfortunately, our data does not contain contraceptive use histories; thus we cannot include contraception as a variable in our model. Nevertheless, we should keep in mind the role of contraception when analyzing the relationship between fertility and abortion and how changes in reproductive behaviour are fundamentally influenced by changes in the pattern of contraception.

\section{Data and methods}

\subsection{Data}

This study uses data on pregnancies and their outcomes which were collected throughout Ukraine by the Demographic and Health Survey conducted from July to November of 2007 (UDHS 2007). This is a nationally representative survey of 6,841 women and 3,178 men aged 15 to 49 . The UDHS provides the unique possibility of exploring detailed reproductive histories of women (including abortions), that cannot be obtained from current Ukrainian statistics. In collecting the histories, each woman was first asked about the total number of pregnancies by pregnancy outcome: live births, stillbirths, miscarriages, and induced abortions, and after that, an event-by-event pregnancy history was recorded (including the month and year of termination, and the outcome of each pregnancy). The response rate for women was $92 \%$.

\subsection{Method}

To study the relationship between fertility and abortion, we first focus on first abortions, which constitute a significant part of all abortions in Ukraine (about $45 \%$ according to the data from UDHS). Our first analysis estimates the risk of first abortion and examines the factors affecting this risk focusing on the role of parity. We employ event-history analysis which makes it possible to study the dependence between the processes under study and the other phenomena which are 
considered as interactive events (Hoem 1976; Blossfeld et al. 2007; Hoem and Kostova 2008).

The process - transition to first abortion - starts at age 15 and ends when a woman has a pregnancy terminated by a first induced abortion. Women who do not experience abortion are censored at the time of interview. Time is measured in months. We excluded from the analysis thirteen cases with abortions undergone by women below the age of 15 years and three missing responses. Finally, our data set contains 6,825 subjects and 2,167 events (first induced abortions).

We use a proportional hazard model with a piecewise constant baseline hazard in order to estimate a risk of first abortion. The model is generally expressed as:

$h(t \mid x)=h_{0}(t) \times \exp \left(\beta_{1} x_{1}+\beta_{2} x_{2}\right)$

where $h$, a hazard rate, is a function of baseline hazard $h_{0}$ and the regression coefficients $\beta$ that measure the effects of time-constant and time-varying covariates $x_{1}$ and $x_{2}$ on the hazard rate. The baseline intensity of this model is age of the woman. Age is divided into the following five age groups: $15-19,20-24,25-29,30-34,35$ years and more. According to our expectations, the age pattern of abortion should be related to the specific character of family formation and childbearing in Ukraine, in particular early age at first birth.

Second, we employ competing risk hazard models to measure the risk of live birth versus the risk of terminating pregnancy by induced abortion. The competing risk model provides a better way to analyzing the changing relationships between fertility and abortion, by enabling us to analyze the importance of the decline in abortion compared to the decline in live births and how this relationship changed over time. In addition, we specify different models by parity. We model the process to the first, second and third conception that ended either with a live birth or abortion. For the first pregnancy, our process is time to first conception which begins at age 15 and ended in abortion or live birth. Because there is relatively little variation in the outcome of first pregnancies (which overwhelmingly end in live births), we are more interested in the relationship for second conceptions. We examine the effects of having one child on the outcome of a second pregnancy whether it is a predictor of terminating this pregnancy by abortion. We excluded all childless 
women and women with first pregnancies ending with abortion, stillbirth or miscarriage.

Duration since first birth is served as process time. It is identical with the age of the first child since we do not account for the death of a child. Similarly, transition to third pregnancy is measured from second child, so that we excluded cases with first and second pregnancies resulting in abortion, stillbirth or miscarriage.

Following our interest in examining the relationship between fertility and abortion and changes in abortion-parity relations over time, we propose two main hypotheses:

H1: Before the breakup of the Soviet Union, Ukrainian women largely avoided terminating first pregnancies. However, after the breakup of the Soviet Union, abortion was used to postpone childbearing;

H2: Abortions have continuously been used to postpone second births, rather than stop childbearing after second birth.

\subsection{Explanatory variables}

Our main explanatory variables are parity and period; both are time-varying covariates: Number of children at the time of first abortion: no children, one child, two children, three children and more.

Calendar period. Calendar period provides a measure of the social and economic changes in Ukraine before and after the break-up of the Soviet Union and their impact on the contraception and fertility behaviour. According to official statistics, we expect to find that the risk of abortion in Ukraine has been declining rapidly along with fertility decline since the beginning of the 1990s. The years are divided into the five groups: 1974-84, 1985-89, 1990-94, 1995-99, 2000-07.

We also include in our model birth cohorts of women as a time-constant variable. Accordingly, we assume that older cohorts of women are more exposed to the risk of experiencing abortion than women in younger cohorts. The following birth cohorts are considered: 1957-69, 1970-74, 1975-79, and 1980-92. 


\subsection{Control variables:}

Region of residence. This variable, the region in which the respondent was interviewed, is very important since previous studies revealed pronounced regional differentials in fertility in Ukraine (Naselennya Ukrainy 2008). The lowest fertility rates have been observed in industrially developed and urbanized Eastern region as well as in the South where women were most likely to postpone motherhood and had a higher mean age of entry into motherhood than their counterparts living in the Western region of Ukraine. This variable should be time-varying; however, we include it as a time-constant variable in order to introduce considerable regional environmental influence on reproductive behaviour in Ukraine. Accordingly, five geographical areas were selected: North, South, Central, East, and West. Each area consists of several administrative divisions out of the total 27 administrative regions (oblasts) in Ukraine (see Appendix 1).

Place of residence. We are also particularly interested in the controlling impact of place of residence on risk of first abortion. We expect urban residence to have an increasing effect on the risk of first abortion compared to women in rural settlements. Similar to region of residence, we consider this variable as a time-constant and distinguish four categories: urban areas are divided into large cities (capital city and cities with over one million population), small cities (population between 50,000 and one million), and towns (other urban areas); the fourth category is countryside.

Religious affiliation. As sexuality and birth behaviour is often based on religious beliefs, it has been suggested that religion may affect the decision for having a child and refusing abortion, even if the conception is unwanted. We distinguish between four religion categories: Orthodox Christian, Catholic Christian, other, and no religion. Orthodox is the dominant religion in Ukraine and used as a reference category. The category of "other" includes Protestant Christian, Islam, Judaism and other small categories. We anticipate some variation in abortion risk by religious affiliation with decreasing risk of abortion for Catholics and increasing risk for those who reported no religion.

Finally, two main models are estimated. The first model includes the following covariates: age of woman, number of children at the moment of first abortion, region of residence, place of 
residence, religion affiliation. Distribution of exposures for variables is presented in Appendix 2. Additionally, we employed the following set of interaction terms: age of woman and period, number of children at the moment of first abortion and cohort. The second model is the competing risk model measuring the risk of abortion versus live birth by pregnancy order and controlled for region of residence, place of residence and religion affiliation.

\section{Results}

\subsection{Pregnancy, abortion and childbearing: general analysis}

The data collected throughout the survey are used for a crude estimation of the total fertility rates (TFR) and the total abortion rates (TAR) for the five-year and ten-year periods preceding the survey. Total abortion rates by order are calculated in a manner analogous to the calculation of fertility rates by parity ${ }^{2}$. According to the survey, the TFR in 1997-02 and 2002-07 did not change substantially, hovering around 1.25 births per woman (see Table 2). However, Table 2 illustrates that different parity-specific fertility rates produced the same outcome: TFR1 was higher in 19972002, but TFR2 was higher in 2002-07. This trend provides evidence that fertility in Ukraine is now shifting towards the postponement of first births coupled with the recovery of second and higher parity births that were postponed during the 1990s. This also provides evidence that second and higher birth rates were the most sensitive to family policy measures enacted by the Ukrainian government in 2005 .

By contrast, total abortion rates have showed a clear downward trend over the observed periods: it fell from 1.09 in 1997-02 to 0.50 in 2002-07. This decline is observed across all orderspecific abortion rates. The results indicate that the most remarkable decrease occurred in the second and third-abortion rates, but a drop in first abortion rate also substantially contributed to lowering the total abortion rate. As a consequence, the total fertility rate in 1997-02 was 1.2 times higher than the total abortion rate, but in 2002-07 this gap widened to 2.5 times.

\footnotetext{
${ }^{2}$ The TAR by order is interpreted as the number of abortions by order a woman would have in her lifetime if she experienced the currently observed age-specific abortion rates during her childbearing years.
} 


\section{Table 2 in about here}

Table 3 presents the distribution of pregnancies by outcome and order of pregnancy. The proportion of pregnancies resulting in a live birth declines with increasing pregnancy order, from 0.89 for first pregnancy to 0.32 for pregnancy orders $4+$. In contrast, the proportion of pregnancies terminated by induced abortion increases by pregnancy order substantially and only one third of fourth-order and higher-parity pregnancies resulted in a live birth. The impact of miscarriage and stillbirth is quite small.

\section{Table 3 in about here}

\subsection{Age-profile of first abortion: effect of early childbearing}

Almost half of women (48\%) in Ukraine have experienced at least one abortion in their lifetime (measured through the survivor function). The highest risk of first abortion is observed at ages 20-24 and the risk falls significantly after 30 years of age (as women have abortions they are removed from the population at risk). The first abortion risk in age groups 15-19 and 25-29 is about one third lower than that at age 20-24 (see Table 4). This age pattern of abortion reflects some peculiarities about the timing of childbearing in Ukraine. In particular, the ages at which women give birth do not vary much: fertility for all births peaks at age 20-24 years. As childbearing is concentrated in young ages and women give birth to a first child in their early 20s, subsequent pregnancies during the reproductive age are often terminated by induced abortions. Also, the risk of abortion for teens is much lower than that for 20-24-year olds but is as high as that for 25-29-yearolds. This is in contrast to some developed countries, where the largest share of abortions is concentrated among single women at very young ages (before age 20), when they begin having sexual relations without adequate contraception (Sedgh et al. 2007; Jones et al. 2008).

\section{Table 4 in about here}




\subsection{Period changes: decreases in abortion over time}

Our results show a strong period effect on the risk of first abortion in Ukraine. Two points are worth mentioning.

First, the risk of first abortion has been declining over time (see Table 4). A gradual decline in abortion risk is observed throughout the 1990s, and a sharp drop in abortion risk occurred only after 2000. Compared to the dramatic decline in fertility after the collapse of the USSR, estimated risks of first abortions decreased at a slower pace.

Second, we have found that the decline in first abortion risk is observed across almost all age groups (see Figure 3). Accordingly, the risk of first abortion at age 20-24 between 2000 and 2007 was reduced by 1.9 times compared to the risk prior to 1985 . For women aged $25-29$, the risk of first abortion in 2000-07 is also markedly lower than for their counterparts in 1974-84. However, the risk for women at age 15-19 does not show a clear downward trend. The abortion risk in the youngest age group even rose over the first half of 1990s, and started to decline only in the mid1990s.

Period effects are larger for women in their 20s and the decrease in first abortion risk over the last decade has been largely driven by positive changes in these age groups rather than among adolescents. This could result from an increase in the proportion of adolescents at risk of pregnancy through being sexually active. Since the break-up of the USSR, Ukraine as other post-soviet countries, is witnessing sexual revolution with radical changes in moral values and sexual behaviour (Kon 1995). Some recent studies on sexual behaviour in Ukraine showed that attitudes towards sexual relations have become more liberal (UNDP 1997; HBSC Report 2008). Along with greater sexual freedom, there has been a downward trend in the age at first intercourse and more liberal attitude to premarital sex. According to our estimation, the median age at first sexual intercourse among Ukrainian women fell across age cohorts, from 19.2 years for women born between 1957 and 1969 to 18.1 years for those born in 1980 to 1989 . Adolescents start their sexual life an earlier age and are often not aware of how to care for their health. Therefore, women who engaged in early sexual activity were exposed to greater risks of unwanted pregnancy and subsequent induced 
abortion. After a real improvement in contraceptive use and public health campaigns focusing on condoms the risk of first abortion among teens started to decline.

\section{Figure 3 in about here}

\subsection{The link between first abortion and childbearing}

Our findings reveal that there are profound differences in first abortion risk for women with children compared to women who have not yet had children, but the risk for mothers by parity varies much less. Entering motherhood increases the risk of first abortion substantially. Table 4 shows that women with two children are at the highest risk of first abortion. The first abortion risk jumps by 10.7 times for parity-two mothers in comparison to those with no children. We also found a first abortion risk about 9.8 times higher for parity-one women and 10.1 times higher risk for those having three or more children (compared to childless women).

Another important point is that Ukrainian women are unlikely to have an abortion before they give birth to their first child. Ukrainian women strongly believe that aborting a first pregnancy may lead to infertility, and therefore they prefer to take their first pregnancy to term, whether it was planned or not. This may be one of the reasons for early first childbearing in Ukraine (Perelli-Harris 2005).

\subsection{Shift in first abortion pattern by parity and cohort}

To further address these issues, Figure 4 provides estimates of the effect of the interaction between number of children and cohort. Using cohort analysis seems to be reasonable assuming that different cohorts hold different attitudes towards abortion as they have experienced different economic and social conditions at the time they had their first abortion.

Our results show that the risk of first abortion for childless women is substantially below the risk for women with children for all cohorts of women born during the years 1957-1992. More interesting are changes in abortion risk across cohort by parity. Figure 4 indicates that the women 
born prior to 1975 have the higher first abortion risk after having the second child, rather than after the having the first one. In contrast, among the women born after 1975, the risk of abortion for mothers with one child is found to be higher than for those with two children. This remarkable shift in fertility-abortion relations towards having the first abortion after the first birth supports our second hypothesis. We suggest that the younger cohorts tend to use abortion for timing and spacing of childbearing purposes, especially for postponement of second child, while the older cohorts stop childbearing after second birth by means of abortion.

\section{Figure 4 in about here}

\subsection{The role of control variables.}

The association between first abortion and control variables is also of interest, even though we urge caution in interpretations, since control variables are measured at the time of the interview. We found strong differences in regional patterns of abortion, in particular between West and other regions of Ukraine. Women living in the West have 3.0-3.2 times lower risk of first abortion compared to those living in the South and Central regions (see Table 4). This seems to be surprising because the survey data indicate that current use of modern contraceptives in the East region is almost twice as high as in the West region, where the risk of abortion is three times lower than that in the East (UDHS 2007). Nevertheless, URHS 1999 and official statistics also indicate simultaneously low percentages of women with abortion and modern contraceptives use in the West compared to other regions. Thus, the low abortion risk in this region may be linked not to the balance between traditional and modern contraceptives, but to factors other than contraception practice. In particular, higher percentages of rural population and Catholics living in the West are associated with higher fertility rates. As more women take pregnancies to term, they do not need to rely on contraception or abortion.

Surprisingly women who live in the capital and large cities have the lower first abortion rates. We would have expected that urban women are more "modernized" and accepting of 
abortion, as is typical of the "Second Demographic Transition" (Surkyn and Lesthaeghe 2004), but again, this study shows how different Ukraine is from other developed countries. Instead, the findings suggest that family planning and health services are more accessible for women in large cities compared to smaller urban areas and the countryside; thus residence in large cities contributes to lower risk of abortion. As expected, the relative risk of first abortion is lowest for Catholics compared to Orthodox Christians, but unexpectedly, the risks are also lower for women who reported no religion. Given that the majority of Ukrainian women identify as Orthodox Christian $(81 \%)$, it may be that religious affiliation is of less importance that religiosity, or church attendance and other expressions of belief.

We also tested the possible effect of educational attainment on the risk of first abortion since education is well-known substantial predictor of reproductive behaviour. Unfortunately, our data set does not contain completed educational histories and we used highest educational level attended as a time-constant variable. This might be the reason of why there appeared no differences in abortion risk by education and our results were non-significant.

\subsection{Competing risks by pregnancy order: first abortion versus live birth}

In this section we turn to model 2: competing risks model for pregnancy outcomes. Figure 5 depicts absolute risk of first abortion relative to the corresponding absolute risk of live birth. One should keep in mind that we compare only first abortion risk with the live birth risk for the orderone, order-two and order-three pregnancies. It means that all women are at the risk of abortion at first pregnancy, but at second and third pregnancies we consider somewhat selective group of women: these are the women with one or two children who are exposed to the risk of first abortion.

\section{Figure 5 in about here}

Taking into consideration the findings of model 1, it is not surprising that the risk of abortion increases dramatically with pregnancy order. While the role of abortion at first pregnancy is of minor importance, women at second and third pregnancies (i.e. women with one and two 
children respectively) are at considerably higher risk of terminating these pregnancies by induced abortions; so abortions disproportionately affects second and higher parity births in Ukraine. More interesting is that the highest risk of abortion is observed for women who get pregnant within a short interval after a previous child birth. For second conceptions that occurred about two years after a first birth, the risk of abortion is as high as that of a live birth, and for third conceptions soon after second birth, the risk of abortion is considerably higher than that of birth. Thus, the birth interval has a strong impact on the risk of first abortion: the shorter the interval between conceptions, the higher the risk of abortion.

Another important result is that the peak for both second and third births is clearly visible at five-six years after a previous birth. This pattern differs from that in many Western countries. First, Ukrainian women have a longer period between second and third births compared to their Western counterparts who are more likely to have second and higher parity births about 2-3 years after previous ones. According to the UDHS data, only $13 \%$ of second and higher order births occur after a birth interval of less than two years. On the other hand, there are shorter birth intervals for fourth or higher order births. Second, early transition to subsequent pregnancies is associated with a higher risk of first abortion in Ukraine. If a woman conceives within in 2-3 years after a second or third birth the pregnancy is at a higher risk of termination, while in Western countries higher-order pregnancies are at a higher risk of birth.

\section{Figure 6 about here}

Two-way interactions between calendar period and type of outcomes are presented at the Figure 6. There were rapid declines in second and third parity births from the end of $1980 \mathrm{~s}$, while first birth risk started to decline only in the 2000s. The latter is not related to the decline in abortion because the risk of abortion at first pregnancy remained at a relatively stable low level throughout the observed period. The relationship between fertility and abortion seems to be more complicated at second and third pregnancies. A drop in abortion risk generally coincided with a drastic decline in second and third parity births risk in the 1990s; however, the pace and the extent of the decline 
somewhat differed: the decrease in first abortion risk at second pregnancy looks to be steeper than for third pregnancy. First abortion risk at second pregnancy was as high as that of live birth in the mid-1980s and fell below considerably thereafter. In contrast, the risk of abortion at third pregnancy has exceeded the corresponding risk of live birth over the whole period. According to our estimation, in 2000-07 the risk of terminating second pregnancy by abortion was almost twice lower than that of live birth and for third pregnancy, abortion risk was as high as a corresponding risk of live birth. Thus, a general decline in first abortion risk over the last decade has been determined by a substantial decrease in the risk of abortion at second and third pregnancies.

As said before, risk of first abortion in the capital and large cities in Ukraine is lower than in small cities and the countryside. A puzzling finding is that this is not observed for all pregnancy orders: women in large cities are more likely to have a first abortion at second and third pregnancies compared to their counterparts living in the countryside (see Figure 7 and Appendix 3). Among the possible explanations for this is that second and higher parity pregnancies are rather rare in large cities compared to others and first abortion risk there might be to a large extent determined by abortion at first pregnancies. Figure 4 reflects how competing risks distinguish by pregnancy order and place of residence: women living in small cities are at the highest risk of terminating second and third pregnancies; women living in towns take second pregnancies to term but tend to abort third pregnancies, and those who live in the countryside are more likely to avoid abortions at the first three conceptions.

\section{Figure 7 in about here}

Parity-specific abortion pattern in Ukraine also differs by region. Fertility and abortion behaviour in the East, Centre, North and South of Ukraine is relatively homogeneous, while in the Western region it is completely different (see Figure 8 and Appendix 4). Unlike in other regions, entering motherhood as well as subsequent childbearing (up to parity three) does not substantially affect the first abortion risk in the West; it still remains below the live birth risk. This reduction of abortion risk in the Western region is not due to an increased use of modern contraceptives, but 
simply due to an increased likelihood that a pregnant woman will choose to let her baby live. We would expect that the West-East differences in mentality (like level of religiosity, for example) in Ukraine are likely to influence individual's reproductive perceptions and practices, and lead to differential responses to an unwanted pregnancy. Therefore, the risk of abortion depends not only how many children a woman already has, but also on other social and cultural factors.

\section{Figure 8 in about here}

\section{Conclusions}

Our analysis shows that relationships between fertility, abortion and contraception are complex and not straightforward during the transition to low fertility. Ukraine has followed its own path with respect to low fertility and abortion has played an important role.

In our study we used individual-level data and exploited retrospective pregnancy histories obtained from a national representative survey UDHS 2007. Given the well-known problem of obtaining reliable information on abortion retrospectively (Philipov et al. 2003), there might be some concerns about the quality of the data used for our estimation. Indeed, many studies in different countries indicated substantial under-reporting of abortions in surveys (Jones and Forrest, 1992; Huntington et al. 1993). Inaccuracy of respondents' answers may be related to negative perceptions and attitudes towards abortion. As abortion has been a hotly debated public issue in many Western countries, women tend to underreport the number of abortions (Anderson et al. 1994). By contrast, in Ukraine this topic seems to be less problematic. This is due to the societal acceptance of abortion in post-soviet countries, where abortion became a part of every-day life and is usually discussed openly. Abortion has long been a legal method of birth control in Ukraine and women are usually not hesitant to report it. Although some inaccuracy of abortion reporting is possible, comparisons with official statistics suggest that the data set used here is rather complete, and we feel our results are not distorted by underreporting (UDHS 2007). 
Summarizing our findings, we suggest four conclusions regarding the interplay of fertility, abortion and contraception in Ukraine.

First, we assume that a rapid decline in fertility in Ukraine in the 1990 has been achieved through contributions of both abortions and the slow adoption of new contraceptive behaviour. The risk of abortion was exceptionally high until 1990, and the low fertility during that time may have been possible to maintain with widespread and easy access to abortion. After the break-up of the USSR, simultaneous declines in both fertility and abortion rates were accompanied by shifts towards modern contraception use. However, of considerable importance for the interpretation of these findings is that the contraception composition in Ukraine remains far from "perfect" in terms of the use of high effective birth control methods. While residents of Western and Northern Europe frequently use modern contraceptives, in Ukraine the reluctance to adopt the pill, reliance on condoms, and liberal attitudes to abortion increase the risk of unwanted pregnancy and make abortion an acceptable alternative when contraception fails.

Second, our results support other findings that abortion is avoided before first birth (PerelliHarris 2005; Muresan 2008), Possibly because of fears of fertility in later life, women take their first pregnancies to term regardless of whether the pregnancy is wanted or not. On the other hand, early age at first birth and longer period of exposure translate into higher risk of additional pregnancies which may increase the risk of abortion.

Third, unlike in countries of the West, where abortions are used to postpone the beginning of childbearing, in Ukraine abortions are widely practiced by women with children. Our analyses showed that the risk of first abortion not only increases by parity dramatically, but also changes across cohort. In particular, the older cohorts tend to use abortion for stopping childbearing after a second birth, while the young cohorts are more likely to have a first abortion in order to postpone childbearing after a first birth. This shift in the timing of first abortion seems to support our second hypothesis, which proposed that abortion specifically contributed to fertility decline in Ukraine in the 1990s, primarily through the postponement or elimination of the second child. 
Fourth, Ukrainian women do not space second and third parity births in a manner similar to their Western counterparts and this is reflected in the timing of parity-specific abortions. As second and third children typically have a longer interval between births (5-6 years), closely spaced pregnancies are at the highest risk of abortion. This is opposite of fertility behavior in Western countries, where women tend to have a shorter interval between first and second births.

A further aspect that should be mentioned with regard to the diverging relationship between abortion, fertility and contraception comes from the regional heterogeneity of abortion in Ukraine. There is a large gap in the first abortion risk between the West of Ukraine and other regions. The lowest abortion risk in the West region is combined with the higher level of traditional contraceptives use (UDHS 2007). Possibly, a high level of religiosity among rural populations found in the West has created a cultural environment unfavourably disposed towards abortion and is a determining factor of the higher fertility in this region. Hence contraceptive practice should not be overestimated as the only decisive factor behind the high risk of abortion in Ukraine.

Finally, our analysis also provides evidence that first abortion risk started to decline only after 2000. These results are different from the official trend showing a rapid decline in total abortion rates starting in 1990. One possible explanation for this is that a great number of abortions (probably mini-abortions) were performed in private clinics throughout the 1990s and were not registered. Alternatively, the number of higher-order abortions may have decreased more substantially than first abortions. Thus, additional research is needed to solve this question.

In conclusion, the case of Ukraine shows that countries can achieve very low fertility without a "contraceptive revolution" or the simultaneous adoption of contraception and abortion. As in Italy, modern technology in Ukraine has not been essential for fertility control. Instead, the decline to very low fertility has been achieved through alternate means: to some degree natural methods and condoms, but primarily abortion. Our study shows that approaches to contraception during the Soviet period brought about long-term consequences for reproductive health. We suggest that the decline to very low fertility in Ukraine in the 1990s was substantially affected by abortion because of insufficient use of modern contraceptives. And, unfortunately, it is still too early to claim 
that the "abortion culture" has already disappeared. Considering that abortion causes a number of serious complications due to the lack of high-quality abortion services in Ukraine (WHO 2008), and repeat abortions are one of the main causes of infertility (Zhylka et al. 2001), the high level of abortions is cause for concern. Thus, we argue that further measures need to be taken in order to promote responsible reproductive behaviour. Not only avoiding births, but avoiding unwanted pregnancies must be placed at the core of family planning programs. 


\section{References}

Agadjanian, V. (2002). Is "abortion culture" fading in the former Soviet Union? Views about abortion and contraception in Kazakhstan. Studies in Family Planning 33(3): 237-248.

Agadjanian, V. and Qian, Z. (1997). Ethnocultural identity and induced abortion in Kazakstan. Studies in Family Planning 28(4): 317-329.

Anderson B. (1991). The role of abortion in fertility decision in the Soviet Union: results analysis of data from Soviet emigrants. Research Report, No. 91-231.

Anderson, B.A., Katus, K., Puur, A., Silver, B.D. (1994). The validity of survey responses on abortion: evidence from Estonia. Demography 31(1): 115-132.

Avdeev, A. (1994). Contraception and abortions: trends and prospects for the 1990s. In: Lutz, F. et al. (eds.) Demographic trends and patterns in the Soviet Union post-soviet countries before 1991. Routledge, London, N.Y.: 131-149.

Blayo, C. (1995). “L’évolution du recours a l'avortement en France depuis 1976.” Population 50(3): 779-810.

Blossfeld, H.P., Golsch, K. and Rohwer, G. (2007). Event history analysis with Stata. Mahwah, NJ. Lawrence Erlbaum.

Bongaarts, J. (1978). A framework for analyzing the proximate determinants of fertility. Population and Development Review 4(1): 105-132.

Bongaarts, J. and Westoff, C.F. (2000). The potential role of contraception in reducing abortion. Studies in Family Planning 31(3): 193-202.

Caldwell, J. C. and Schindlmayr, T. (2003). Explanations of the fertility crisis in modern societies: A search for commonalities. Population Studies 57: 241-263.

Dalla Zuanna, G. (2001). The banquet of Aeolus: A familistic interpretation of Italy's lowest low fertility. Demograhic Research Special Collection 3:133-162.

Dalla Zuanna, G., De Rose, A. and Racioppi, F. (2005). Low fertility and limited diffusion of modern contraception in Italy during the second half of the twentieth century. Journal of Population Research 22(1): 21-48.

David, H.P. (1992). Abortion in Europe. 1920-91: A public health perspective. Studies in Family Planning 23(1): 1-22.

De Rose, A., Racioppi, F. and Zanatta, A.L. (2008). Italy: Delayed adaptation of social institutions to changes in family behaviour. Demographic Research 19(19): 665-704.

Frejka T., Sobotka, T., Hoem, J.M., Toulemon, L. (2008). Summary and general conclusions: childbearing trends and policies in Europe. Demographic Research 19(2): 5-14.

Frejka, T. (1983). Induced abortion and fertility: a quarter century of experience in Eastern Europe. Population and Development Review 9(3): 494-520. 
Frejka, T. (2008). Birth regulation in Europe: completing the contraceptive revolution. Demographic Research 19(5): 73-84.

Goldstein, J. R., Sobotka, T. and Jasilionienè. A. (2009). The end of „lowest-low“ fertility? Presentation at 74th Annual Meeting of the Population Association of America 2009. Detroit, MI (United States), April 2009.

Gribaldo, A., Judd, M.D. and Kertzer, D.I. An imperfect contraceptive society: Fertility and contraception in Italy. Population and Development Review 35(3): 551-584.

HBSC Report (2008). Inequalities in young people’s health. WHO, 133 p.

Henshaw, S.K., Singh, S. and Haas, T. (1999). The incidence of abortion worldwide. International Family Planning Perspectives 25 (Suppl.): S30-S38.

Hoem, J. M. (1976). The statistical theory of demographic rates: A review of current developments (with discussion). Scandinavian Journal of Statistics 3(4), 169-185.

Hoem, J. M., and Kostova, D. (2008). Early traces of the second demographic transition in Bulgaria: A joint analysis of marital and non-marital union formation. Population Studies $62(3), 1-13$.

Huntington, D., Mensch, B., Toubia, N. (1993). A new approach to eliciting information about induced abortion. Studies in Family Planning 24(2): 120-124.

Jones, E. and Forrest, J.D. (1992). Underreporting of abortion in surveys of US women: 1976 to 1988. Demography 29(1): 113-126.

Jones, R.K., Zolna M.R.S., Henshaw. S.K., Finer. L.B. (2008). Abortion in the United States: incidence and access to services, 2005. Perspectives on Sexual and Reproductive Health 40(1):6-16.

Kohler, H-P., Billari, F.C. and Ortega, J.A. (2002). The emergence of fertility in Europe during the 1990s. Population and Development Review 28: 641- 680.

Kon, I. S. (1995). The Sexual Revolution in Russia: From the age of the czars to today. New York: The Free Press.

Marston, C. and Cleland J. (2003). Relationship between contraception and abortion: a review of the evidence. International Family Planning Perspectives 29(1): 6-13.

Muresan C. (2008). Impact of induced abortion on fertility in Romania. European Journal of Population 24: 425-446.

Naselennya Ukrainy (2008). Narodzhuvanist v Ukraini u konteksti suspilno-transformatziinyh prozesiv (Population of Ukraine. Fertility in Ukraine in the context of societal transition). Kyiv, IDSD. - 288 p. [in Ukrainian].

Perelli-Harris, B. (2005). The path to lowest-low fertility in Ukraine. Population Studies 59(1): 5570. 
Perelli-Harris, B. (2008a). Family formation in post-Soviet Ukraine: changing effects of education in a period of rapid social change. Social Forces 87 (2): 767-794.

Perelli-Harris, B. (2008b). Ukraine: on the border between old and new in uncertain times. Demographic Research 19(29): 1145-1178.

Philipov, D. (2003). Fertility in times of discontinuous societal change. In: Kotovska, I.E. and Jozwiak, J. (eds.). Population of Central and Eastern Europe: Challenges and Opportunities. Warsaw: Statistical Publishing Department: 665-690.

Philipov, D., Andreev, E., Kharkova, T., Shkolnikov, V. (2003). Induced abortion in Russia: recent trends and underreporting in surveys. European Journal of Population 20: 95-117.

Popov A.A, (1996). Family planning and induced abortion in post-Soviet Russia of the early 1990s: Unmet needs in information supply. In: DaVanzo. J. and Farnsworth. G. (eds.). Russia's Demographic Crisis. Santa Monica, CA: RAND: 84-112.

Popov A.A. (1991). Family planning and induced abortion in the USSR: basic health and demographic characteristics. Studies in Family Planning 22(6): 368-377.

Remennik. L. (1991). Epidemiology and determinants of induced abortion in the USSR. Social Science and Medicine 33(7): 841-848.

Rossier, C. (2003). Estimating induced abortion rates: A review. Studies in Family Planning 34(2): 87-102.

Rossier, C., Michelot, F., Bajos, N. and the COCON Group (2007). Modeling the process leading to abortion: an application to French Survey data. Studies in Family Planning 38(3): 163-172.

Sedgh, G., Henshaw, S.K., Singh, S., Bankole, A., Drescher, J. (2007). Legal abortion worldwide: incidence and recent trends. Perspectives on Sexual and Reproductive Health 39(4): 216225.

Sobotka, T. (2008). The diverse faces of the Second Demographic Transition in Europe. Demographic Research 19(8): 171-224.

Sobotka, T., Št’astná, A., Zeman, K., Hamplová, D., Kantorová, V. (2008). Czech Republic: A rapid transformation of fertility and family behaviour after the collapse of state socialism. Demographic Research 19(14): 403-454.

Steshenko, V. (2001). Fertility decline // Demographichna kryza v Ukraini (Demographic crisis in Ukraine). Kyiv, Institute of Economics: 296-319 [In Ukrainian].

Steshenko, V. and Irkina, T. (1999). Some aspects of the demographic situation in Ukraine: reproductive health and family planning. United Nations. $-31 \mathrm{p}$.

Stloukal. L. (1999). Understanding the 'abortion culture' in Central and Eastern Europe. In: David H.P. (ed.) From abortion to contraception. A resource to public policies and reproductive behavior in Central and Eastern Europe from 1917 to the present, Westport, Connecticut, Greenwood Press: 23-37. 
Stover, J. (1998). Revising the proximate determinants of fertility framework: what have we learned in the past twenty years? Studies in Family Planning 29 (3): 255-67.

Surkyn, J., and Lesthaeghe, R. (2004). Value orientations and the Second Demographic Transition (STD) in Northern, Western and Southern Europe: Demographic Research 3(3): 45-86.

Trevitt, J. and Astone, N. (2009). Describing repeat abortions in Eurasia: a comparison of women in Kazakhstan, Uzbekistan, and Kyrgyzstan. Presentation at 74th Annual Meeting of the Population Association of America 2009. Detroit, MI (United States), April 2009.

UDHS (2007). Ukraine Demographic and Health Survey 2007. Ukrainian Centre for Social Reforms, State Statistical Committee of Ukraine, Ministry of Health of Ukraine, and Macro Intrenational Inc., Calverton, Maryland, USA. - 335 p.

UNDP. Ukraine Human Development Report (1997). The health of women and children in Ukraine. Kyiv. - 152 p.

URHS (1999). Ukraine Reproductive Health Survey 1999. Final report. KIIS, USAID, Centers for Diseases Control and Prevention, $41 \mathrm{p}$.

Van de Kaa, D.J. (1994). The second demographic transition revisited: theories and expectations. In.: Beets, G. et al. (eds.) Population and family in the Low Countries 1993: Late fertility and other current issues. NIDI/CBGS Publication, 30, Pennsylvania/Amsterdam: 81-126.

Westoff, C.F. (2000). The substitution of contraception for abortion in Kazakhstan in the 1990s. DHS Analytical Studies No. 1. Calverton, Maryland, USA: ORC Macro.

Westoff, C.F. (2005). Recent trends in abortion and contraception in 12 countries. DHS Analytical Studies No. 8. Calverton, Maryland, USA: ORC Macro.

Westoff, C.F. and Ryder, N.B. (1977). The contraceptive revolution. Princeton: Princeton University Press.

Westoff, C.F. and Serbanescu, F.I. (2008). The relationship between contraception and abortion in the Republic of Georgia. Further analysis of the 1999 and 2005 Reproductive Health Surveys. Calverton, Maryland, USA: Macro International Inc.

World Bank (2006). Socioeconomic impact of HIV/AIDS in Ukraine. Washington. - 112 p.

WHO (2008). Aborty i contraceptsia v Ukraine. Strategicheskaya otsenka politiki, programm i issledovanii [Abortion and contraception in Ukraine. A strategic assessment of policy, programme and research issues]. - Health Care Ministry of Ukraine, WHO. - 88 p. [In Russian].

Zakharov, S.V. and Sakevich, V. I. (2007). Osobennosti planirovania semi i rozhdaemost v Rossii: contraceptivnaya revolutsia - svershivshiisya fact? [Family planning and fertility in Russia: contraception revolution - the real fact?] In: Roditeli i deti, muzhchiny i zhenschiny v semie $\mathrm{i}$ obschestve [Parents and children, men and women in family and society], edited by 
Maleva T. and Sinyavskaya O. Moscow, Independent Institute for Social Policy [In Russian].

Zhylka, N., Irkina, T., Steshenko, V. (2001). Reproductive health in Ukraine. - Kyiv, Health Care Ministry. $-68 \mathrm{p}$. 


\section{Tables and Figures}

Figure 1. Abortion rates in Ukraine and selected European countries, per 1000 live births

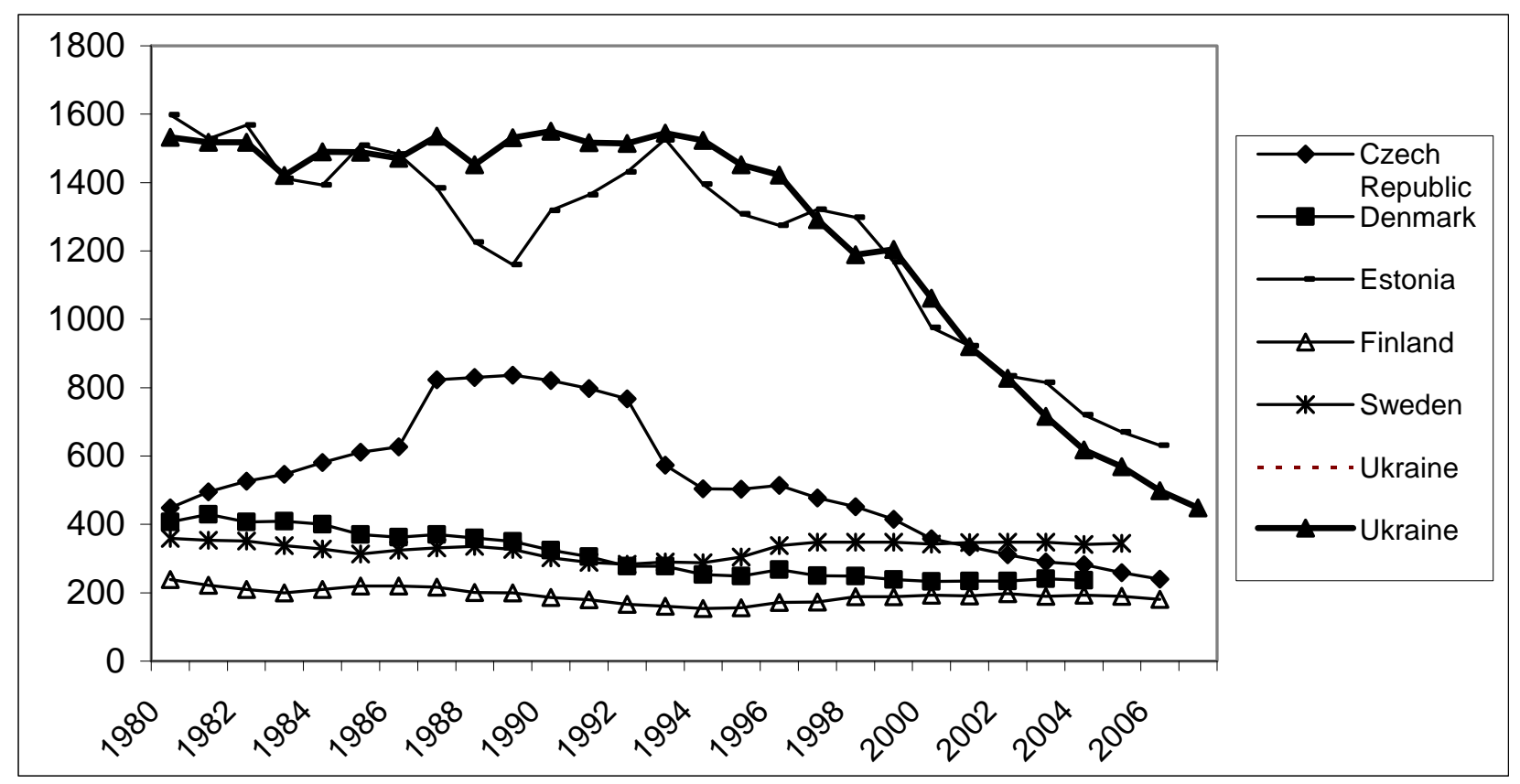

Source: WHO HFA-DB. 
Figure 2. Total abortion rates (TAR) and total fertility rates (TFR) in Ukraine: 1980-2007

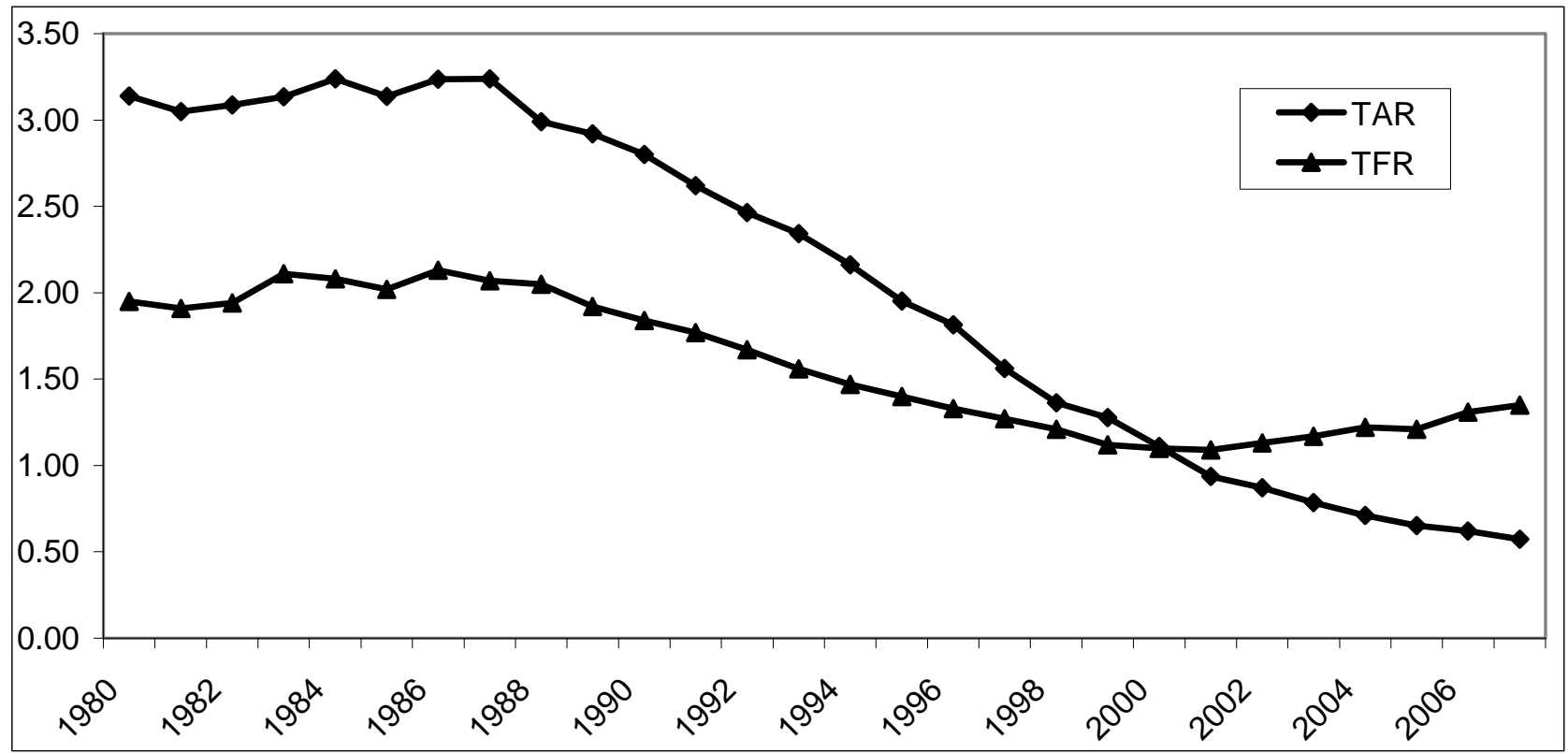

Source: Author's calculations based on statistics from Health Care Ministry and Statistical Offices of Ukraine.

Note: As age-specific abortion data are not available in Ukraine, the total abortion rate was estimated from general abortion rates for women aged 15-49. 
Table 1. Current use of contraception: percentage distribution of currently married women by number of living children, 2007

\begin{tabular}{|l|l|l|l|l|}
\hline & \multicolumn{2}{|l|}{ Number of living children } & \multirow{2}{*}{ All women } \\
\hline & $\mathbf{0}$ & $\mathbf{1 - 2}$ & $\mathbf{3}$ & 66.7 \\
\hline Any method & 39.5 & 71.0 & 62.9 & $\mathbf{4 7 . 5}$ \\
\hline Any modern method & $\mathbf{3 1 . 7}$ & $\mathbf{5 0 . 8}$ & $\mathbf{3 6 . 5}$ & 17.7 \\
\hline - IUD & 1.4 & 20.6 & 12.1 & 23.9 \\
\hline - Pill & 23.1 & 24.3 & 19.4 & 4.8 \\
\hline - Female sterilization & 6.2 & 4.8 & 2.9 & 0.6 \\
\hline - Others & 0.0 & 0.6 & 2.1 & 0.5 \\
\hline Any traditional method & 1.0 & 0.5 & 0.0 & $\mathbf{1 9 . 1}$ \\
\hline - Withdrawal & $\mathbf{7 . 8}$ & $\mathbf{2 0 . 1}$ & $\mathbf{2 6 . 5}$ & 10.3 \\
\hline - Rhythm & 4.9 & 10.7 & 15.3 & 7.2 \\
\hline - Folk method & 2.1 & 7.6 & 10.2 & 1.6 \\
\hline Not currently using*** & 0.8 & 1.8 & 1.0 & $\mathbf{3 3 . 4}$ \\
\hline So & 60.5 & $\mathbf{2 9 . 1}$ & $\mathbf{3 7 . 0}$ & \\
\hline
\end{tabular}

Source: UDHS 2007. 
Table 2. Total fertility rates (TFRs) and total abortion rates (TFRs) by order for the five-year and ten-year periods preceding the survey

\begin{tabular}{|c|c|c|c|c|c|c|}
\hline & $\mathrm{TFR}_{1}$ & $\mathrm{TFR}_{2}$ & $\mathrm{TFR}_{\mathbf{3}}$ & $\mathrm{TFR}_{\mathbf{4}}$ & TFR $_{5+}$ & TFR \\
\hline $1997-02$ & 0.775 & 0.376 & 0.080 & 0.015 & 0.012 & 1.257 \\
\hline \multirow[t]{2}{*}{$2002-07$} & 0.714 & 0.417 & 0.078 & 0.023 & 0.020 & 1.253 \\
\hline & TAR $_{1}$ & $\mathrm{TAR}_{2}$ & $\mathrm{TAR}_{3}$ & TAR $_{4}$ & TAR $_{5+}$ & TAR \\
\hline 1997-02 & 0.437 & 0.350 & 0.194 & 0.078 & 0.026 & 1.085 \\
\hline \multirow[t]{2}{*}{$2002-07$} & 0.215 & 0.158 & 0.064 & 0.044 & 0.016 & 0.497 \\
\hline & $\mathrm{TFR}_{1} / \mathrm{TAR}_{1}$ & $\mathrm{TFR}_{2} / \mathrm{TAR}_{2}$ & $\mathrm{TFR}_{3} / \mathrm{TAR}_{3}$ & $\mathrm{TFR}_{4} / \mathrm{TAR}_{4}$ & $\mathrm{TFR}_{5+} / \mathrm{TAR}_{5+}$ & TFR/ TAR \\
\hline 1997-02 & 1.77 & 1.07 & 0.41 & 0.19 & 0.46 & 1.16 \\
\hline $2002-07$ & 3.32 & 2.64 & 1.22 & 0.52 & 1.25 & 2.52 \\
\hline
\end{tabular}

Source: Author's calculations based on UDHS 2007.

Table 3. Pregnancy outcomes by order of pregnancy: weighted percentages

\begin{tabular}{|l|c|c|c|c|}
\hline Pregnancy order & Live birth & $\begin{array}{c}\text { Induced } \\
\text { abortion }\end{array}$ & Stillbirth & Miscarriage \\
\hline First & 88.74 & 6.46 & 0.43 & 4.38 \\
\hline Second & 52.12 & 40.94 & 0.37 & 6.57 \\
\hline Third & 40.35 & 52.27 & 0.5 & 6.89 \\
\hline Fourth and higher & 32.04 & 63.31 & 0.16 & 4.49 \\
\hline
\end{tabular}

Source: UDHS 2007 
Table 4. Relative risk of first abortion (Model 1).

\begin{tabular}{|c|c|}
\hline Covariate & Relative risk \\
\hline \multicolumn{2}{|l|}{ Age of women, years } \\
\hline $15-19$ & $0.62 * * * \quad(0.05)$ \\
\hline $20-24$ & 1 \\
\hline $25-29$ & $0.61 * * *(0.03)$ \\
\hline $30-34$ & $0.31 * * *(0.03)$ \\
\hline $35+$ & $0.12 * * *(0.02)$ \\
\hline \multicolumn{2}{|c|}{ Number of children at the moment of abortion } \\
\hline No children & 1 \\
\hline One child & $9.78^{* * *}(0.73)$ \\
\hline Two children & $10.68 * * *(0.84)$ \\
\hline Three and more children & $10.13 * * *(0.94)$ \\
\hline \multicolumn{2}{|l|}{ Calendar period } \\
\hline $1974-1984$ & $1.76^{* * *}(0.14)$ \\
\hline $1985-1989$ & $1.94 * * *(0.14)$ \\
\hline 1990-1994 & $1.79 * * *(0.12)$ \\
\hline 1995-1999 & $1.75^{* * *}(0.12)$ \\
\hline $2000-2007$ & 1 \\
\hline \multicolumn{2}{|l|}{ Region of residence } \\
\hline North & $2.93 * * *(0.25)$ \\
\hline Central & $3.04 * * *(0.25)$ \\
\hline East & $2.86 * * *(0.25)$ \\
\hline South & $3.22 * * *(0.26)$ \\
\hline West & 1 \\
\hline \multicolumn{2}{|l|}{ Religion affiliation } \\
\hline Orthodox Christian & 1 \\
\hline Catholic Christian & $0.68 * *(0.11)$ \\
\hline Other & $0.90(0.12)$ \\
\hline No religion & $0.87 * *(0.07)$ \\
\hline \multicolumn{2}{|l|}{ Place of residence } \\
\hline Large city & 1 \\
\hline Small city & $1.46^{* * *}(0.12)$ \\
\hline Town & $1.19 * *(0.11)$ \\
\hline Countryside & $1.25 * *(0.11)$ \\
\hline \multicolumn{2}{|l|}{ Model fit } \\
\hline Initial LL & -5049.75 \\
\hline Final LL & -4099.17 \\
\hline
\end{tabular}

Note: ${ }^{* \star} p<0.01,{ }^{* \star} p<0.05,{ }^{*} p<0.1$. Standard errors in parentheses.

Source: Author's calculations based on UDHS 2007. 
Figure 3. Relative risk of first abortion by age and period

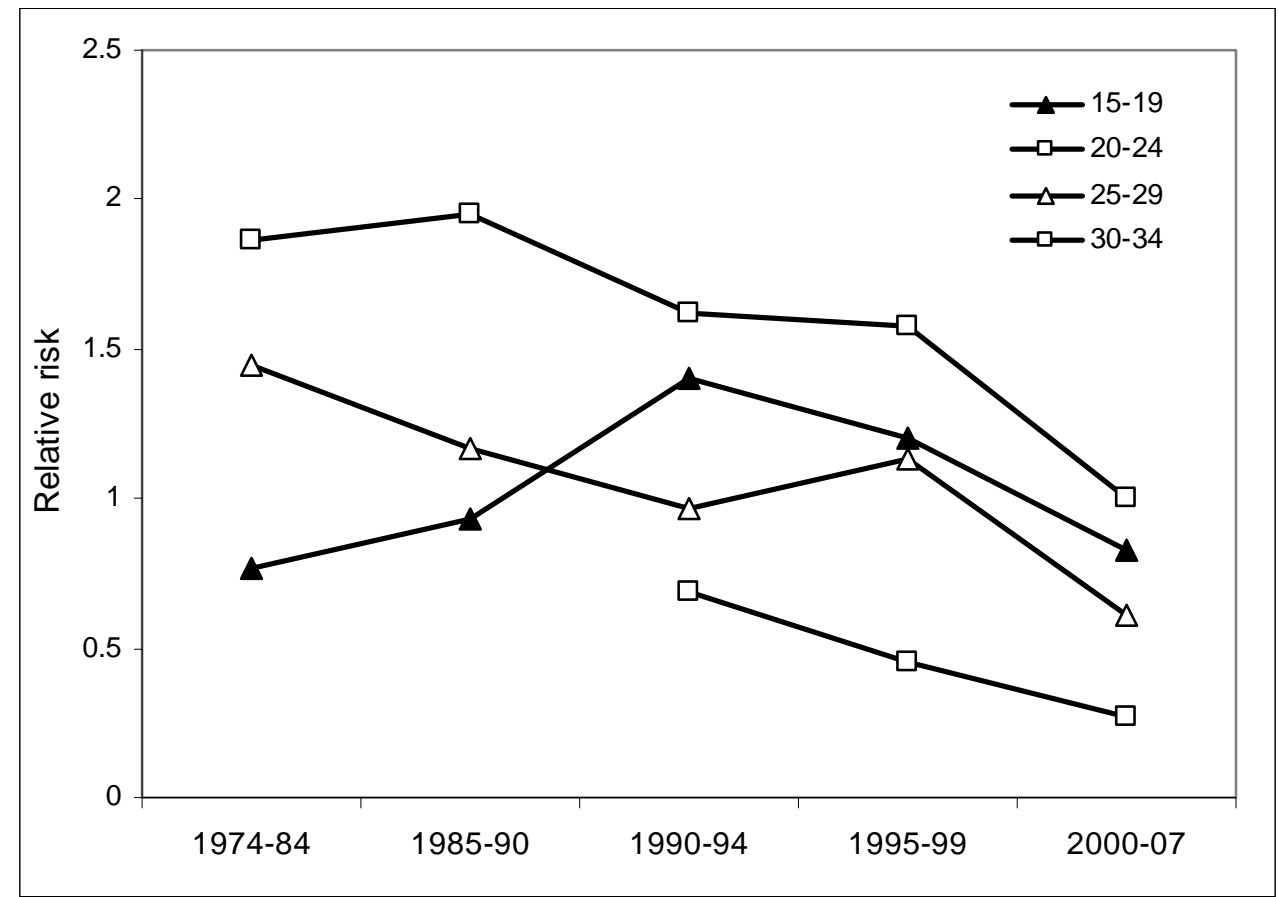

Reference: aged 20-24 in 2000-2007.

Controlled for: religion, region, place of residence, number of children at the moment of abortion. Source: Author's calculations based on UDHS 2007. 
Figure 4. Relative risk of first abortion by cohort and number of children at the moment of abortion

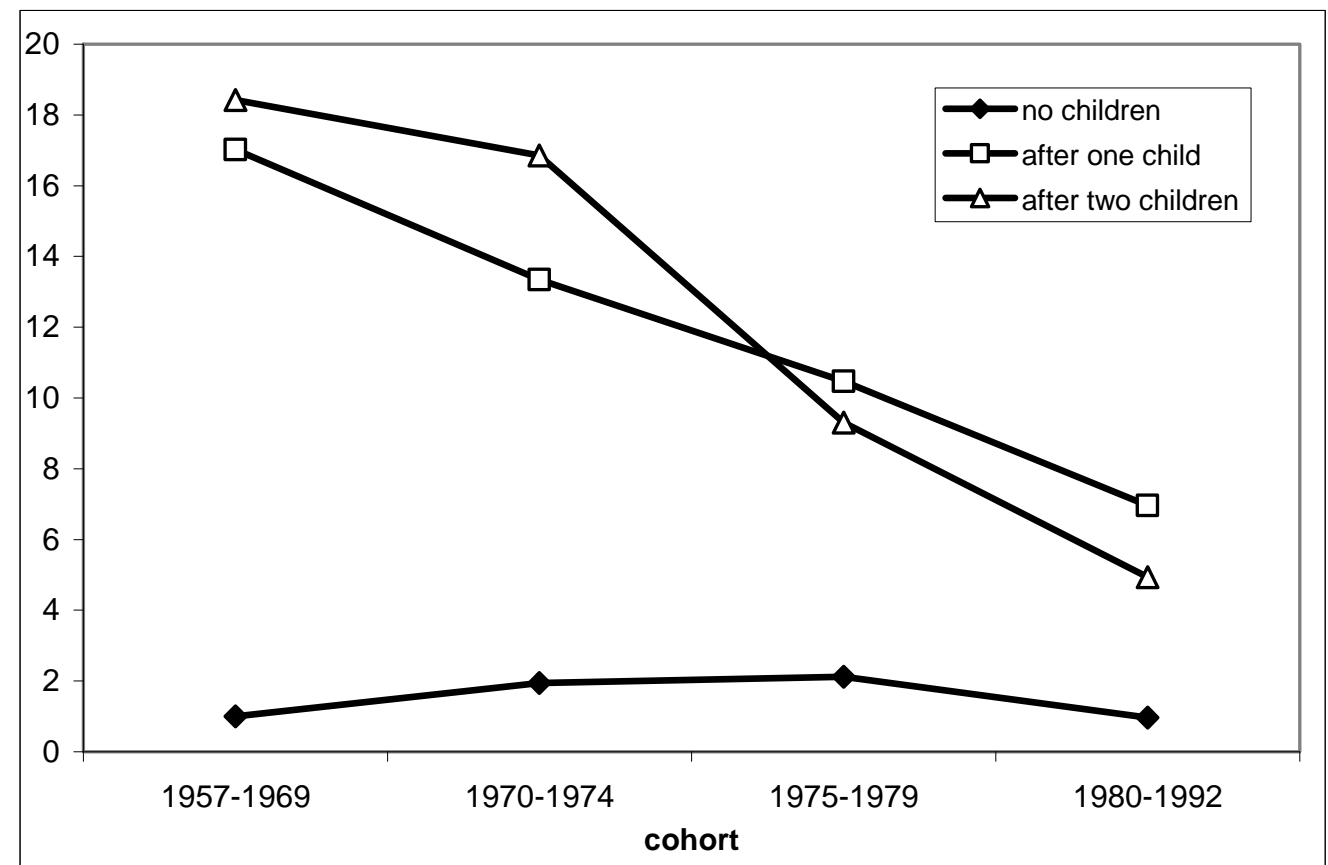

Reference: no children, cohort 1957-1964

Controlled for: age of women, religion, region, place of residence.

Source: Author's calculations based on UDHS 2007. 
Figure 5. Age profiles of first, second and third pregnancies, by type of outcome: abortion versus live birth. Absolute risks per 1,000 person-months.
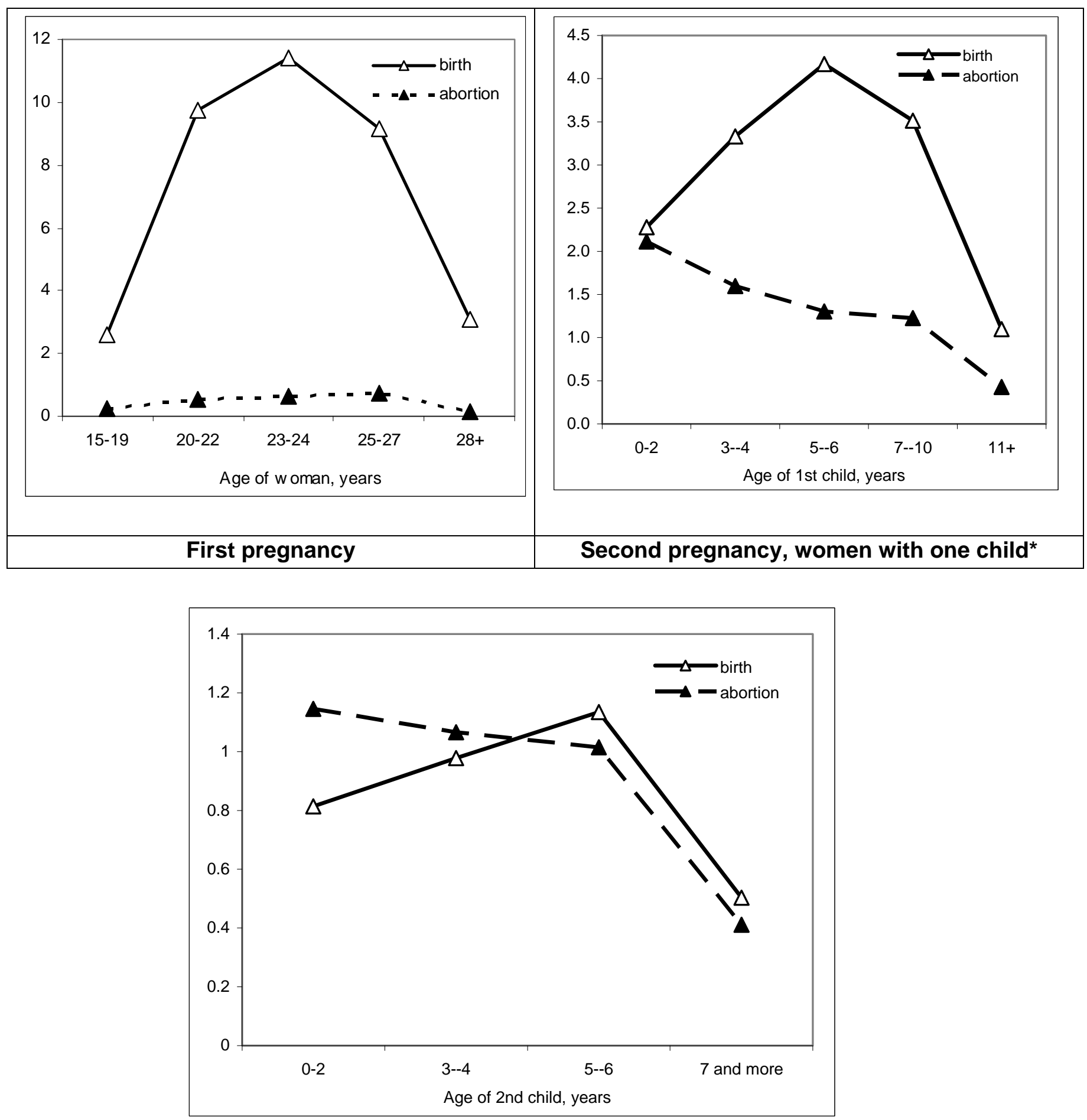

Third pregnancy, women with two children**

Notes:

* excluding women with first pregnancies ending with abortion, stillbirth or miscarriage

** excluding women with first and second pregnancies ending with abortion, stillbirth or miscarriage

Controlled for: region, religion and place of residence.

Source: Author's calculations based on UDHS 2007. 
Figure 6. Trends in relative risks of first, second and third pregnancies by outcome: live birth versus abortion.

Reference: risk of live birth in 2000-07 (jointly for both live birth and abortion).
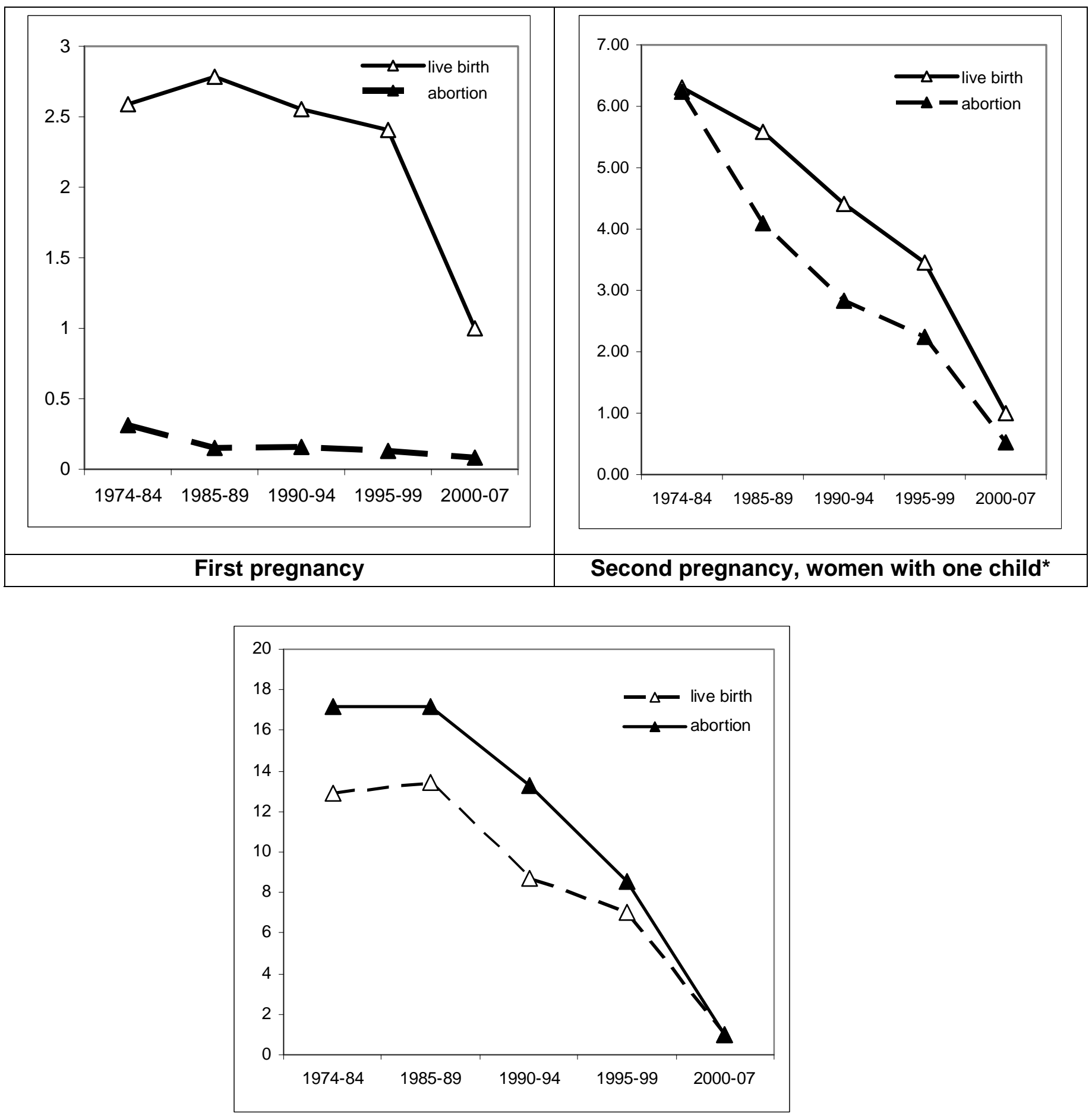

Third pregnancy, women with two children**

Notes:

* excluding women with first pregnancies ending with abortion, stillbirth or miscarriage

** excluding women with first and second pregnancies ending with abortion, stillbirth or miscarriage

Controlled for: region, religion and place of residence.

Source: Author's calculations based on UDHS 2007. 
Figure 7. Risk of abortion relative to that of live birth by pregnancy order* and place of residence

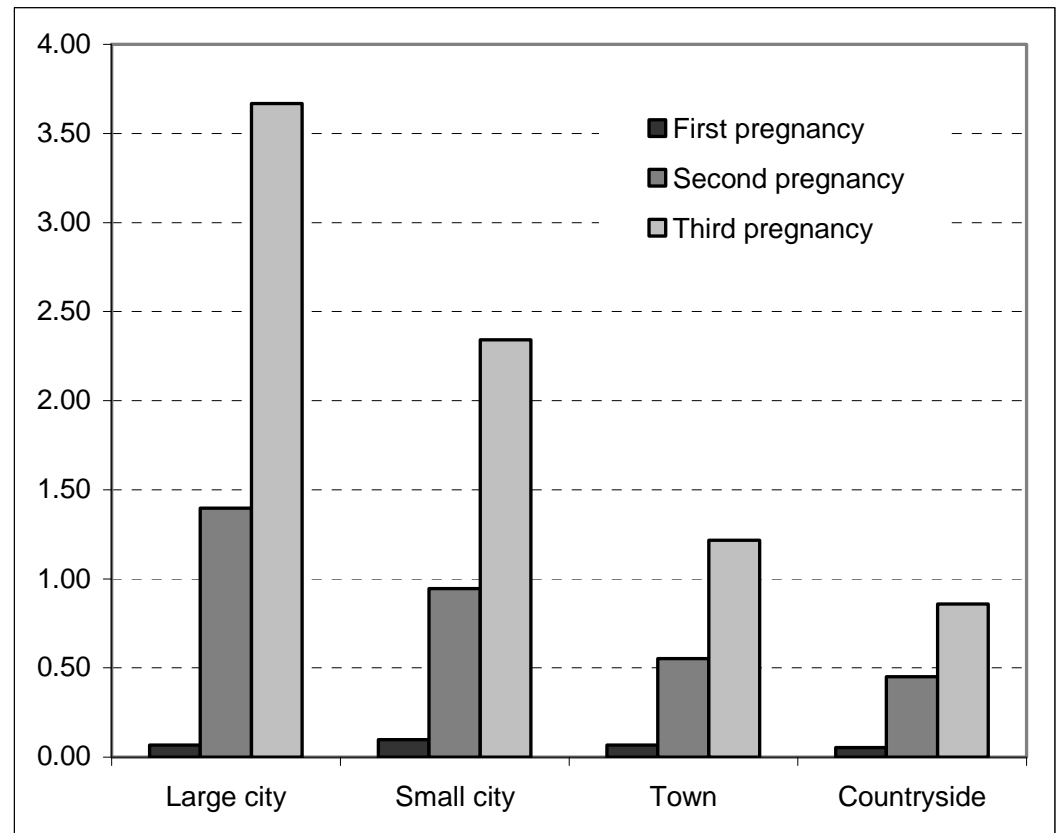

Notes:

* 2nd pregnancy: excluding women with first pregnancies ending with abortion, stillbirth or miscarriage 3rd pregnancy: excluding women with first and second pregnancies ending with abortion, stillbirth or miscarriage

Controlled for: region, religion and place of residence.

Source: Author's calculations based on UDHS 2007. 
Figure 8. Risk of abortion relative to that of live birth by pregnancy order* and region of residence

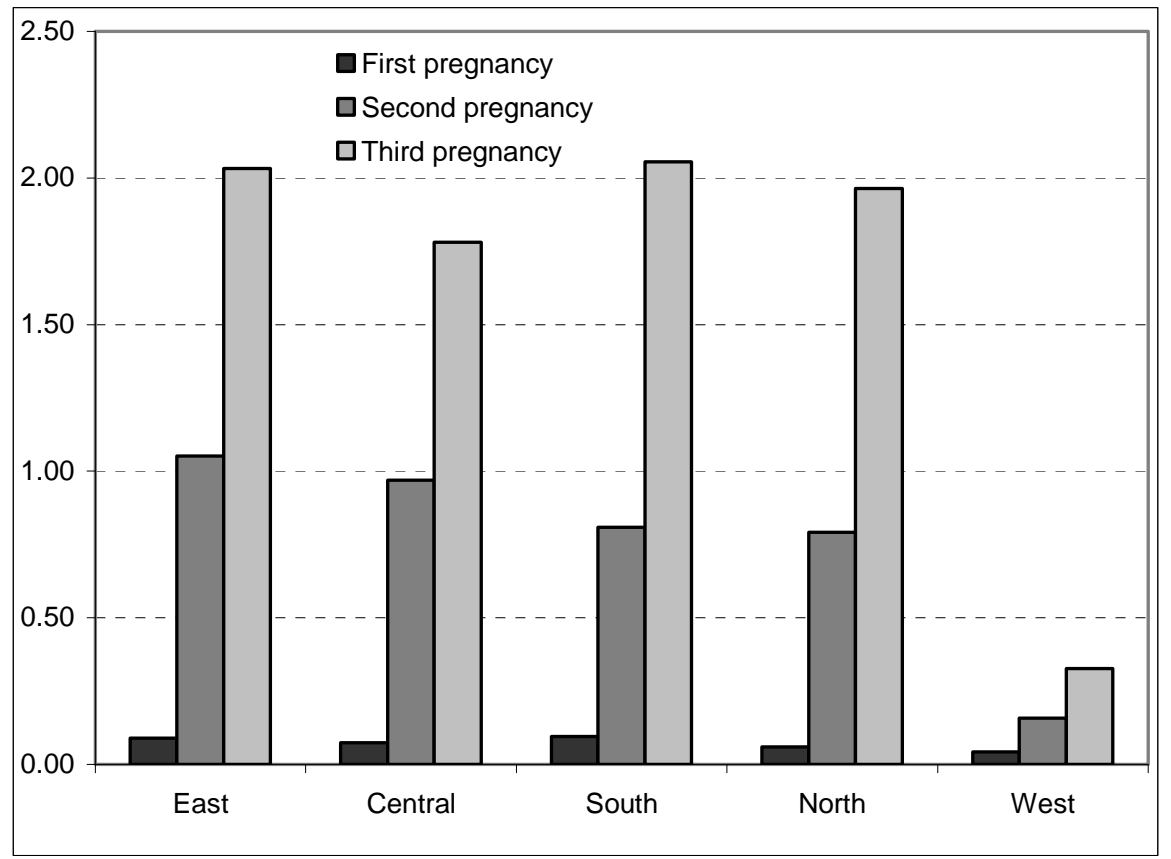

Notes:

* excluding women with first pregnancies ending with abortion, stillbirth or miscarriage excluding women with first and second pregnancies ending with abortion, stillbirth or miscarriage

Controlled for: region, religion and place of residence.

Source: Author's calculations based on UDHS 2007. 


\section{Appendixes}

\section{Appendix 1: Definition of regions}

North: the city of Kyiv, and the regions of Kyiv, Zhytomyr, Sumy and Chernigiv;

Central: the regions of Cherkasy, Poltava, Kirovohrad and Vinnytsia;

South: the Autonomous Republic of Crimea, the city of Sevastopol' and the regions of Odesa, Mykolaiv and Kherson;

East: the regions of Dnipropetrovs'k, Donets'k, Zaporizhzhia, Luhans'k, and Kharkiv;

West: the regions of Ivano-Frankivs'k, Khmel'nyts'kyi, Chernivtsi, L'viv, Rivne, Ternopil', Volyn' and Zakarpattia.

\section{Appendix 2: Distribution of exposures for variables}

\begin{tabular}{|l|c|c|}
\hline & Frequency & \% \\
\hline Age & & 34.56 \\
\hline $15-19$ & 380,322 & 26.05 \\
\hline $20-24$ & 286,745 & 16.62 \\
\hline $25-29$ & 182,904 & 10.73 \\
\hline $30-34$ & 118,132 & 12.04 \\
\hline $35+$ & 132,513 & \\
\hline $\begin{array}{l}\text { Number of children at the time of } \\
\text { abortion }\end{array}$ & & 53.57 \\
\hline No children & 589,619 & 27.65 \\
\hline One child & 304,291 & 15.22 \\
\hline Two children & 167,486 & 3.56 \\
\hline Three and more children & 39,220 & \\
\hline Calendar period & & 15.89 \\
\hline $1974-1984$ & 174,836 & 13.61 \\
\hline $1985-1989$ & 149,820 & 16.33 \\
\hline $1990-1994$ & 179,769 & 18.99 \\
\hline $1995-1999$ & 209,000 & 35.18 \\
\hline $2000-2007$ & 387,191 & \\
\hline Birth cohort & & 52.83 \\
\hline $1965-1969$ & 581,499 & 16.81 \\
\hline $1970-1974$ & 184,966 & 14.15 \\
\hline $1975-1979$ & 155,762 & 16.21 \\
\hline $1980-1989$ & 178389 & 18.10 \\
\hline Region of residence & & 18.35 \\
\hline North & 199,203 & 20.63 \\
\hline South & 227,025 & \\
\hline Central & 201,946 & \\
\hline East & 177,779 & \\
\hline West & 294,663 & \\
\hline Place of residence & 121,715 & \\
\hline Large city & & \\
\hline & & \\
\hline
\end{tabular}




\begin{tabular}{|l|c|c|}
\hline Small city & 324,918 & 29.52 \\
\hline Town & 242,105 & 22.00 \\
\hline Countryside & 411,878 & 37.42 \\
\hline Religion affiliation & & \\
\hline Orthodox Christian & 903,723 & 82.11 \\
\hline Catholic Christian & 677,58 & 6.16 \\
\hline Other & 333,32 & 3.03 \\
\hline No religion & 958,03 & 8.70 \\
\hline
\end{tabular}

Source: Author's calculations based on UDHS 2007. 
Appendix 3: Relative risk of first, second* and third** pregnancies by outcome of pregnancy and place of residence

\begin{tabular}{|c|c|c|c|c|}
\hline Pregnancy order/outcome of pregnancy & Large city & Small city & Town & Countryside \\
\hline \multicolumn{5}{|l|}{ First pregnancy: } \\
\hline - live birth & 1.00 & 1.20 & 1.34 & 1.48 \\
\hline - abortion & 0.07 & 0.12 & 0.09 & 0.08 \\
\hline \multicolumn{5}{|l|}{ Second pregnancy: } \\
\hline - live birth & 1.00 & 1.65 & 1.99 & 2.58 \\
\hline - abortion & 1.40 & 1.56 & 1.10 & 1.16 \\
\hline \multicolumn{5}{|l|}{ Third pregnancy: } \\
\hline - live birth & 1.00 & 1.94 & 2.40 & 3.68 \\
\hline - abortion & 3.67 & 4.54 & 2.92 & 3.16 \\
\hline
\end{tabular}

Notes:

* excluding women with first pregnancies ending with abortion, stillbirth or miscarriage

** excluding women with second pregnancies ending with abortion, stillbirth or miscarriage

Controlled for: region, religion and place of residence.

Source: Author's calculations based on UDHS 2007

Appendix 4. Relative risk of first, second ${ }^{*}$ and third** pregnancies by outcome of pregnancy and region of residence

\begin{tabular}{|l|c|c|c|c|c|}
\hline $\begin{array}{l}\text { Pregnancy order/outcome } \\
\text { of pregnancy }\end{array}$ & East & Central & North & South & West \\
\hline First pregnancy: & \multicolumn{5}{|l|}{} \\
\hline - live birth & 1.00 & 0.96 & 0.97 & 0.95 & 1.00 \\
\hline - abortion & 0.09 & 0.07 & 0.06 & 0.09 & 0.04 \\
\hline Second pregnancy: & \multicolumn{5}{|l}{} \\
\hline - live birth & 0.59 & 0.60 & 0.68 & 0.69 & 1.00 \\
\hline - abortion & 0.62 & 0.58 & 0.54 & 0.56 & 0.16 \\
\hline Third pregnancy: & \multicolumn{5}{|l|}{} \\
\hline - live birth & 0.65 & 0.66 & 0.57 & 0.60 & 1.00 \\
\hline - abortion & 1.32 & 1.17 & 1.11 & 1.23 & 0.33 \\
\hline
\end{tabular}

Notes:

* excluding women with first pregnancies ending with abortion, stillbirth or miscarriage

** excluding women with second pregnancies ending with abortion, stillbirth or miscarriage

Controlled for: region, religion and place of residence.

Source: Author's calculations based on UDHS 2007. 